\title{
The Accidents Caused by Personnel Behavior Violations
}

\author{
Tong Rui, Yang Yingying, Jin Jing, Wang Qinghao, Wang Enlu, Han Lu, Shan Jia, Li Bo, Liu \\ Peng, Zhang Ning
}

Fushun Power Supply Company, Liaoning Electric Power Company Limited, State Grid, China

Keywords: Serious violation, Behavior violation, Cognitive process, Emotional process, Will process

\begin{abstract}
Through the analysis of the violation, we can see that the violation can be divided into serious violation and general violation according to the possible consequences. There are 58 behaviors in violation of regulations. The psychological process consists of three parts: cognitive process, emotional process and will process. The three psychological processes of cognition, emotion and will are interrelated, mutually promoted and unified. Through the analysis of a case, it shows that the problem of personnel violation is prominent, the pertinence and effectiveness of training need to be strengthened, the awareness of safety and risk is not strong. It is necessary to actively carry out the activities of eliminating behavior and violating regulations, so as to make employees realize that "violation of regulations is the source of accidents and violation of regulations is the source of casualties".
\end{abstract}

\section{Introduction}

Behavior violation refers to the unsafe behavior of site operators who violate the rules, regulations, regulations, anti-accident measures and so on in the process of electric power construction, operation, maintenance and other production activities. According to the statistical report of the accident reasons of the State Grid Company, the personal injury and injury caused directly or indirectly by the people's behavior account for $80 \% \sim 90 \%$ of the total number of accidents per year. This paper analyzes the causes of illegal behavior, probes into the manifestation of violation, formulates relevant control measures, maximizes the elimination of all kinds of illegal behaviors in power grid production, and reduces the occurrence of accidents, which is of great practical significance to the healthy, sustainable and stable development of power grid enterprises.

\section{Types of Behavior Violation}

Violations are classified into serious violations and general violations according to possible consequences.

1) Serious violations refer to violations sufficient to cause personal accidents, power grid accidents and equipment incidents.

2) Except for serious violations, they are general violations.

The specific grading standards shall be defined by each unit in combination with the actual production safety.

\section{The Performance of Behavior Violation}

1) The safety helmet was not worn correctly when entering the work site.

2) Engaged in high-altitude work not as stipulated the correct use of seat belts and other high-height anti-fall articles or devices.

3) The operation site has not set up a fence as required. The operator crossed the security fence or crossed the security cordon without authorization

4) Do not use the operation ticket to switching operation according to the regulations.

5) Do not use work tickets as prescribed. 
6) Do not wear insulated gloves when switching operation on the spot. Do not wear insulated boots when inspecting in Thunderstorm Weather or Operating the outdoor high-voltage equipment.

7) Stop and send electricity about time.

8) Unlocking the lock and making switching operation without authorization.

9) The key of the anti-mistake locking device is not used in accordance with the regulations.

10) Delay the execution of dispatching command or insufficient enforcement.

11) The responsible guardian does not perform the duty of guardianship seriously and is engaged in work which is not related to guardianship.

12) Do not check equipment name, number, location, do not perform guardianship system before switching operation or skip and miss project during operation.

13) Do not check the actual position of the equipment according to the regulations, and do not confirm the operation of the equipment during switching operation.

14) No electrical test before installation of ground wire in blackout operation, the installed ground wires do not comply with the requirements and do not install and disassemble the ground wires in accordance with the regulations and order.

15) Missing and wrong hanging(dismantle) the indication plate.

16) Work ticket, operation ticket, work card does not sign according to regulations.

17) Before the start of work, the working controller does not read the work ticket to all the members of the work class, does not define the scope of work and the area of live electricity, failure to account for safety measures or account unclearly, then start work blindly.

18) The work licensor does not arrange and perfect the work site safety measures according to the safety measures and site conditions listed in the work ticket.

19) The operator changes the scope of work, job content, or safety measures that have been set up without authorization.

20) The working controller allows the staff to operate before all the security measures listed in the work ticket were put in place.

21) The working controller handles the formalities of work termination when the work class members are still working or have not been completely evacuated from the work site.

22) The working controller or the work licensor does not go through the work permit and the termination procedure according to the stipulation.

23) Enter the work site and dress incorrectly.

24) After the overhaul is completed, the number of persons and tools is not counted, the persons and objects left behind is not checked before closed wind tunnel cover plates, wind tunnel doors, pressure pipes, volute cases, draft pipes and pressure vessel manholes.

25) Failure to use qualified safety apparatus in accordance with regulations, use of safety apparatus that has not been inspected or has exceeded the testing cycle.

26) Do not use or incorrect use of labor protection supplies, such as the use of grinding wheels, lathe without eye protection glasses, using rotary tools such as drilling machines wearing gloves, etc.

27) Inspection or repair operations, staff or equipment and charged body can not maintain the prescribed safety distance.

28) Do not pull the relevant power supply when Overhauling or disintegrating work in the switch mechanism.

29) Open the protective cover of the rotating equipment in operation. Put hand into the shield of the rotating equipment during operation. Wear gloves or wipes to clean or perform other work on the rotating part.

30) Use Steel scale, leather tape and line ruler (with metal wire) to measure near live equipment.

31) Use metal ladders in the vicinity of live equipment. Failure to use and carry ladders, pipes, etc. In Outdoor substation and high-pressure chamber.

32) No barriers or fences installed in high-pressure tests, no monitoring and shouting during the pressurization process, the high voltage part of the booster equipment was not discharged and short circuited grounding when the wiring changes or the test ends. 
33) When the capacitor is overhauled, the capacitor is not discharged and grounded or the cable test is finished, and the tested cable is not fully discharged.

34) Switch transmission test of relay protection does not inform the operator, on-site maintenance personnel.

35) When working on the relay screen, there is no obvious separation between the operating equipment and the maintenance equipment, or when working on or near the protection plate for a larger vibration, no safety measures are taken to prevent the gate from falling.

36) A wire rope used for coal transporter or donkey engine in leaping operation.

37) No whistle warning or lifting work has no special command before the crane lifting.

38) The safe distance is not enough and effective measures have not been taken in hoisting operation near electrified equipment.

39) During hoisting or pulling, someone lingered and passed from the surrounding, the upper side, the lower side and Inner corner side of the wire rope and under the lifting object. To pass through a person's head or stand under a crane when lifting a heavy object.

40) Gantry crane, tower crane disassembly (installation) process is not strictly in accordance with the prescribed procedures.

41) Leaning or crossing the railing on the high platform and the edge of the hole.

42) Do not set up or use scaffolding as prescribed when working high.

43) Remove hole cover plate, railing, isolation layer without authorization or remove the ancillary facilities without obvious signs and restore them in time.

44) Enter volute and draft tube without anti-drop device and special person monitoring.

45) Use railing, scaffolding, porcelain and other lifting objects.

46) High-rise workers throw equipment and materials up and down.

47) When working high in pedestrian crossings or densely populated areas, there are no fences under the workplace, no guards or other security measures.

48) No one helps the ladder; the ladder is placed on an unstable support or a ladder without anti-skid measures when working on a ladder.

49) Let the person without live working qualification carry on live working.

50) Do not check the line name, bar number, color code before boarding.

51)Do not check the base, root, ladder and cable before boarding.

52) Failure to take measures to prevent the tower from toppling or to suddenly cut off the wire, ground wire, pull wire and so on before setting up a tower, withdrawing a rod, or withdrawing and tightening a line.

53) Fire work does not comply with the provisions of the handling or execution of fire work tickets.

54) Special operation personnel do not hold license to go on duty or allow non-special operations personnel to perform special operations.

55) To weld pressure, live, oil filled containers and pipes before carrying out the relevant formalities.

56) Welding over combustible materials and important equipment, no guardian below, no fire prevention and other safety measures.

57) Flammable, explosive articles or various cylinders are not transported, stored and used in accordance with regulations.

58) Water work does not wear life-saving measures.

\section{A Case of Harm in Behavior Violation}

\subsection{The accident}

From May 8th 2017 to 15th, A Electrician zone does the replacement of insulators on 500kV FengDa No.1 line, the whole line was divided into 6 groups. On May 12th, the work went on to 5th days, the third work group responsible person Zhou, led the operator $\mathrm{Wu}$ (deceased) and other 8 people, carried on replacement of porcelain insulator of No.103 tower with composite insulator. 
After replacement of $\mathrm{V}$ phase composite insulators, workers on the tower $\mathrm{Wu}$ and Xing were ready to install heavy hammers. Xing first went down to the wire end along the soft ladder. At 14:16, In the process of descending along the soft ladder, $\mathrm{Wu}$ accidentally fell to the ground from a height of 33m above the ground, and was taken to the hospital to die.

The accident investigation confirmed that Wu had fastened the safety belt protection rope before descending along the soft ladder, but the buckle was not fastened and checked.

In the process of descending along the soft ladder, instead of adopting the "soft ladder down the line, should be on the side of the soft ladder, should grasp firmly, steadily up and down" operation method, the walking composite insulator foot stepped on the soft ladder down, accidentally fell. The leader of the team looked up and saw that the safety belt protection rope was straining in the air during the $\mathrm{Wu} \times$ fall and then fell to the ground with him.

\subsection{The cause of the accident}

1) The direct cause of the accident is the violation of work class member $\mathrm{Wu}$ (deceased). First of all, after wearing the seat belt, Wu did not check if the safety belt protection rope buckle was fastened, that violates State Grid Company Electric Power Safety Code (Line part) 6.2.2. Secondly, when the ladder falls, it violates the regulations of the working area on the use of the soft ladder.

2) The working controller did not carry out effective supervision, he acquiesced in the illegal operation of the soft ladder, this is the indirect cause of the accident.

\subsection{Problems exposed by the accident}

1) The problem of personnel violation of regulations is prominent. In the case of clear provisions on the use of the soft ladder in the working area, the operators still use the past customary practice, showing disregard for the regulations and requirements, which shows that the work against illegal regulations is not carried out effectively.

2) The pertinence and effectiveness of the training need to be strengthened urgently. The actual operation skills of employees are poor, and the basic skills are lacking.

3) Safety awareness and risk awareness are not strong. The risk up and down the soft ladder is insufficiently estimated, and the use of the soft ladder is not emphasized in the operation instruction and technical process.

\section{Analysis of psychological reasons of behavior violation.}

\subsection{Psychological process and safety}

Human psychological process consists of three parts: cognitive process, emotional process and will process, which are interrelated, mutually promoted and unified.

\subsection{Cognitive process}

Cognitive processes include feeling, perception, memory, thinking, imagination and so on. It is the primary psychological factor affecting human behavior.

\subsection{Emotional process}

Emotional process not only affects work achievement and labor efficiency, but also brings positive or negative effect to safety.

\subsection{Will process}

There are two sides to the process of will: strong will is good for the safety of production, but weak will not only threaten production, and also enlarge the consequence of accident.

\subsection{Personality Psychology and Safety}

Personality psychology is mainly composed of personality tendency and personality psychological characteristics. 


\subsection{Personality tendency}

Personality orientation mainly includes need, motivation, interest, etc. Need and motivation are the most basic causes of human activity, while interest determines the tendency of activity. It is the driving force of human activities and plays a positive and negative role in production safety.

\subsection{Personality psychological characteristics}

Personality psychological characteristics mainly include personality, temperament, ability, etc. Personality is the attitude characteristic of people towards realistic things and accomplishing activities, temperament is the driving force of human psychological activities, and ability is the characteristic of potential possibility for people to accomplish certainactivities. Personality psychological characteristics are relatively stable components in human psychological activities. It is the basic guarantee of enterprise safety work to cultivate the good personality psychological characteristics of the enterprise staff.

\section{Conclusions}

Employees should be made to establish the basic concept of safety and risk awareness, especially to maintain the potential risk of operations to have a clear understanding. Safety and risk are two aspects of the same problem. With risk awareness, there will be a sense of safety. In this way, we will be alert to all kinds of dangerous sources, enhance our sense of responsibility for safety, and we will not make a wrong estimate of all kinds of illegal risks, and will have a sense of risk. You can understand that violation is not zero risk. If the first violation is allowed, there will be a second, third, and even Violation of regulations turns into a habit and universality, and then becomes the corrosive agent of safety production in enterprises. In that way, it will lead to frequent accidents, make power grid enterprises suffer huge losses, and make employees lose their labor ability. It is necessary to make every employee realize that violation of regulations is absolutely not allowed.

It is necessary for employees to understand and grasp the basic psychological characteristics of human beings, the weakness of human nature, to understand why people make mistakes, to understand the relationship between human behavior and motivation, and the relationship between human needs and values. To understand the needs and objectives of enterprises, the relationship between individual needs and business needs, and to align individual needs with the needs of enterprises. Safety is the first need of the enterprise, is the life of the enterprise, to ensure safety is the responsibility of every employee. When employees really know their own personal needs and the needs of the interests of the enterprise, will consciously enforce the operation rules and regulations to eliminate violations. Grass-roots teams and employees at all levels should conscientiously abide by the regulations on safety in production, profoundly realize that "violation of regulations is the source of accidents and violations of regulations are the source of casualties," then actively carry out anti-violation self-examination and self-correction and mutual investigation and mutual correction.

\section{References}

[1] Yu Hongyun, Li Rui. Anti falling technology in high power operation. Beijing: China Electric Power Press, 2008.

[2] Huang Xuenong. Training materials for security managers of power grid enterprises. Beijing: Electronic Industry Press, 2014.

[3] Tian Yuping, Ji Yuliang. Production management and safe production safety. Baishan press, 2009.3

[4] Liu Jinsong. Strengthen outsourcing management; avoid security risk. Baishan press, 2008.5. 